\title{
Alkalosis in Burns in Children
}

\author{
J. A. BLACK, F. HARRIS, E. A. LENTON, R. W. S. MILLER, V. J. CHILD
}

British Medical fournal, 1971, 4, 387-388

\section{Summary}

The acid-base changes in 14 children with severe burns were studied for varying periods after resuscitation. A long-continued metabolic alkalosis was found, which may be due to increased adrenocortical activity.

\section{Introduction}

The changes in acid-base state shortly after severe burns have been extensively studied and it is well recognized that a metabolic acidosis develops rapidly during the shock phase. However, relatively little attention has been given to the later changes in acid-base metabolism. In this investigation we did serial estimations of the acid-base state after initial resuscitation. Since little information was available about the range for blood $\mathrm{pH}$, standard bicarbonate, and $\mathrm{PCO}_{2}$ in normal children, we took a single blood sample, before elective surgery, in a group of children in order to obtain a comparable series of normal values for our age range.

\section{Patients and Methods}

Over a period of 12 months we made serial, usually daily, estimations of the acid-base state on 14 children admitted to Sheffield Children's Hospital with burns of $10 \%$ or more of their body surface. The average period of study was $\mathbf{4 0}$ days, the shortest being five days and the longest $\mathbf{5 0}$ days. The age range was from nine months to eight years and $57 \%$ of the children were between one and four years. We took arterialized capillary blood samples during the mid-morning and the $\mathrm{pH}$ was measured with Radiometer pH meter (Siggaard Andersen et. al., 1960), making temperature corrections when necessary (Siggaard Andersen, 1963). The standard bicarbonate and carbon dioxide tension $\left(\mathrm{PCO}_{2}\right)$ were derived according to the method and nomogram of Siggaard Andersen and Engel (1960). Estimations of plasma sodium, potassium, and urea were also made at the same time as the acid-base determinations.

All patients were resuscitated during the first $\mathbf{4 8}$ hours after the burn with reconstituted freeze-dried plasma in amounts according to the formula of Muir and Barclay (1963). We excluded from this series all patients with known or suspected burns of the respiratory tract. Local treatment of the burned area was by exposure followed by the application of $0.2 \%$ chlorhexidine cream. Children with very extensive burns usually required intravenous fluids during the first week, mainly $0.45 \%$ sodium chloride in $2.5 \%$ glucose. The total fluid intake was adjusted to maintain a minimum output of urine equivalent to $25 \mathrm{ml}$ an hour, making appropriate reduction for the age and size of each child. No alkalinizing or acidifying preparations or fluids were used, with the exception of the citrate contained

\footnotetext{
Children's Hospital, Sheffield, and the Department of Child Health, University of Sheffield

J. A. BLACK, M.D., F.R.C.P., Consultant Paediatrician

J. A. BLACK, M.D., F.R.C.P., Consultant Paediatrician

F. HARRIS, M.D., M.R.C.P., Lecturer in Ch

R. W. S. MILLER, F.R.C.S.ED., Consultant Plastic Surgeon

V. J. CHILD, B.sC., Research Assistant
}

in the plasma. The alkalinizing effect of this citrate would not have influenced acid-base metabolism after the period of resuscitation (E. Lenton, unpublished). Hyponatraemia and hypokalaemia were corrected as soon as they were observed. Two children with extensive burns $(55 \%$ and $60 \%$ of body surface) died.

During the same period 94 children who were admitted for elective operation for tonsillectomy, herniotomy, and various plastic and ophthalmic conditions had a single preoperative estimation of their blood $\mathrm{pH}$, standard $\mathrm{HCO}_{3}$, and $\mathrm{PCO}_{2}$. The same methods were used as in the children with burns. The age range of these children was from three months to 13 years, with $42 \%$ between the ages of one and four years.

\section{Results}

The values for blood $\mathrm{pH}$, standard $\mathrm{HCO}_{3}$, and $\mathrm{PCO}_{2}$ obtained in the 94 control patients are shown in Fig. 1; the means were as follows: $\mathrm{pH} 7.388$ (S.D. 0.027), standard $\mathrm{HCO}_{3} 22.6 \mathrm{mEq} /$ litre (S.D. 1.75), and $\mathrm{PCO}_{2} 37.8 \mathrm{~mm} \mathrm{Hg}$ (S.D. 4.4). The mean $\mathrm{pH}$ is slightly lower than the accepted normal for adults and the range for standard $\mathrm{HCO}_{3}$ is similar to that found in children by Vokac and Vavrova (1968), taking into account that they used venous blood. The mean values for $\mathrm{pH}$, standard $\mathrm{HCO}_{3}$, and $\mathrm{PCO}_{2}$ for the first 28 days after the burn are shown in Fig. 2. The $\mathrm{PCO}_{2}$ values are symmetrically distributed about the mean for the controls, but $\mathrm{pH}$ and standard $\mathrm{HCO}_{3}$ are considerably raised. It should be emphasized that the value given for each day is the mean of a number of results from different patients and therefore there is not the same chemical and biological
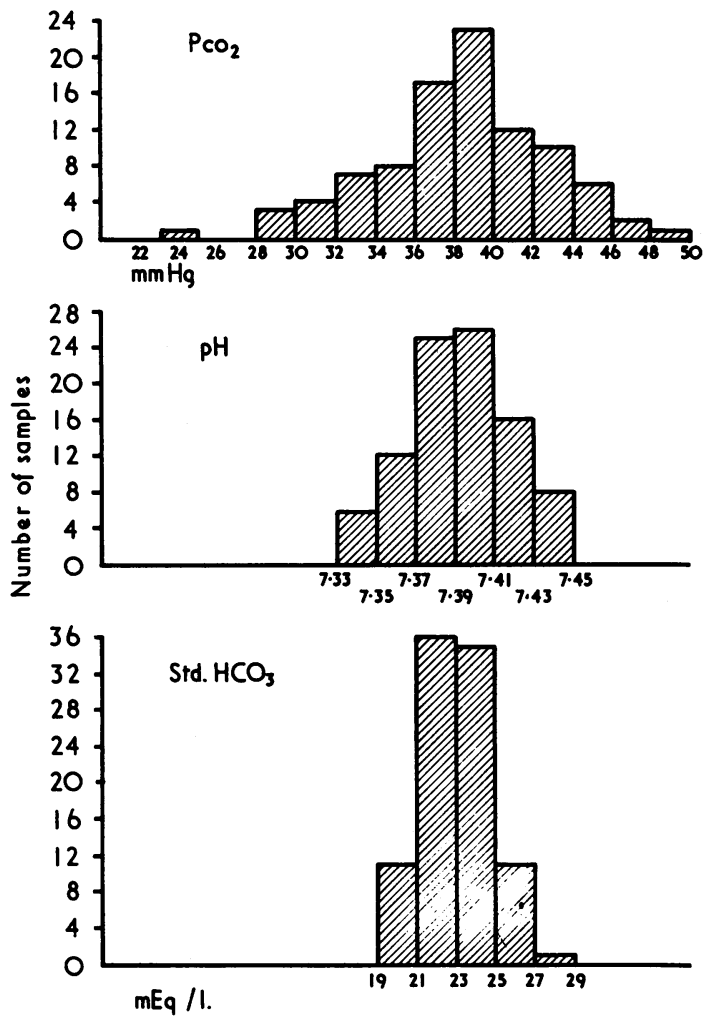

FIG. 1-Values for blood $\mathrm{pH}$, standard $\mathrm{HCO}_{3}$, and $\mathrm{PCO}_{2}$ in 94 control patients. 

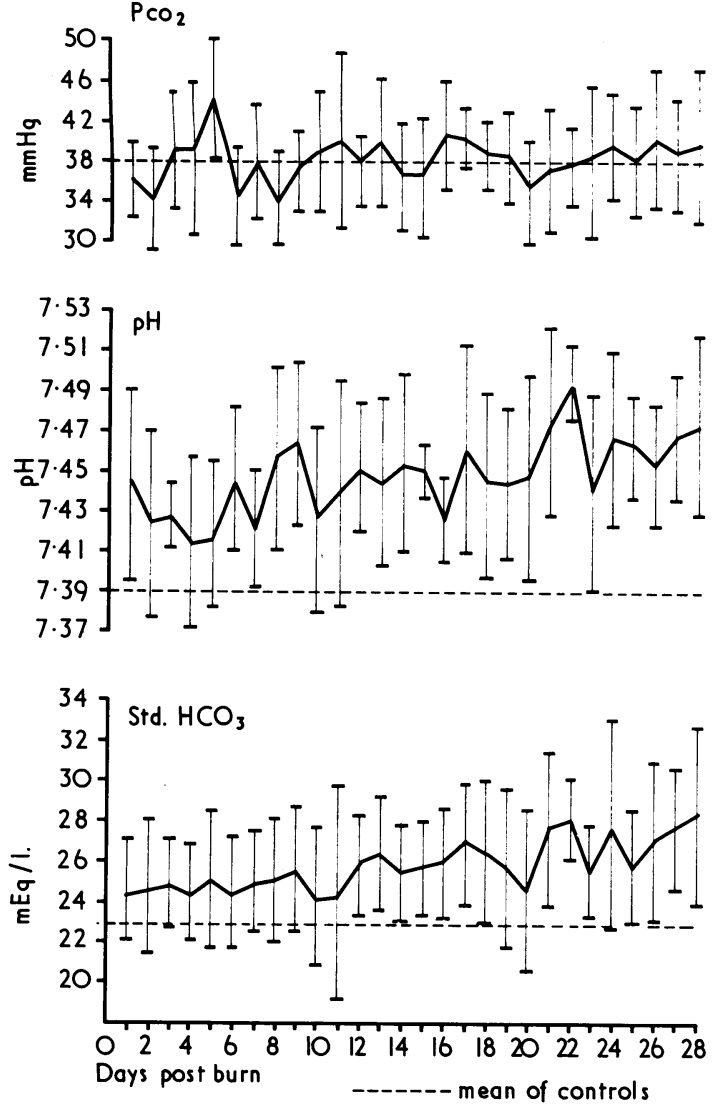

FIG. 2-Mean values for $\mathrm{pH}$, standard bicarbonate, and $\mathrm{PCO}_{2}$ plus and minus one standard deviation, for the first 28 days after the burn.

relationship between $\mathrm{pH}$, standard $\mathrm{HCO}_{3}$, and $\mathrm{PCO}_{2}$ as exists when these values are obtained from a single blood sample. Nevertheless a detailed analysis of the serial results in each patient showed a progressively increasing metabolic alkalosis, with occasional periods of respiratory alkalosis superimposed. In some children this metabolic alkalosis persisted until the burn was almost healed. In Fig. 3 are shown the typical changes
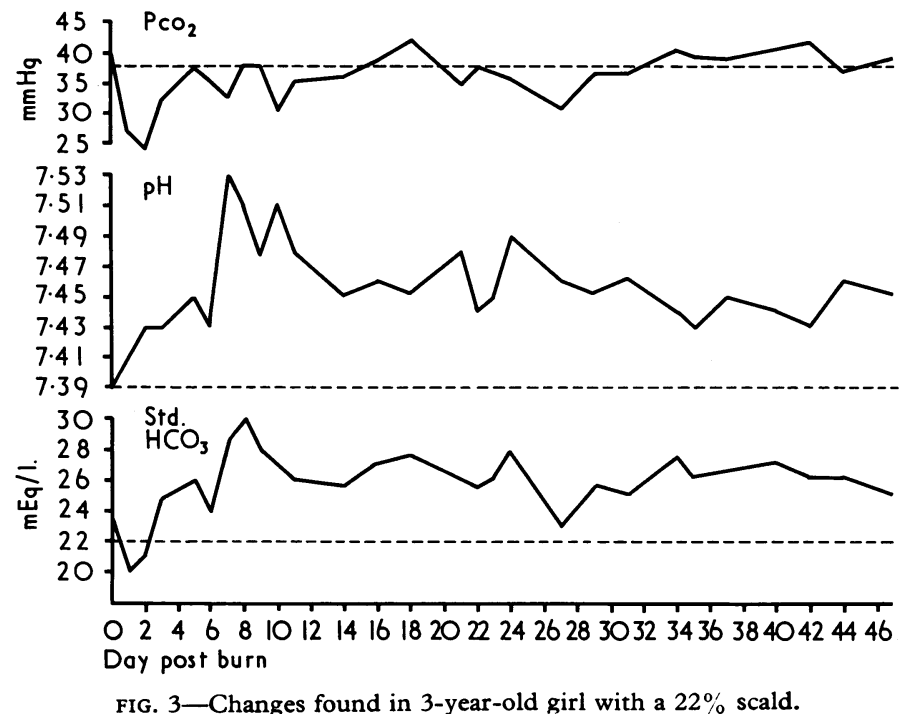

which occurred in a 3 -year-old child with a $22 \%$ scald. No systematic study of urine $\mathrm{pH}$ was made in these cases, but random samples examined during the period of investigation showed a $\mathrm{pH}$ between 6.5 and $7 \cdot 5$.

\section{Discussion}

Part of the reaction to injury is a metabolic alkalosis, which is thought to be due to increased adrenocortical activity. Moore (1955) showed that a similar metabolic alkalosis can be produced by the injection of corticotrophin into healthy volunteers. In contrast to an operation or a single episode of trauma a burn represents a state of prolonged or repeated stress. The plasma 17-hydroxycorticosteroids are considerably raised in these patients (Hume et al., 1956). The metabolic alkalosis which we have observed may therefore be due to stimulation of the adrenal cortex. Since hypokalaemia was promptly corrected it is unlikely that potassium deficiency could have contributed to the alkalosis, though this possibility can be completely excluded only by balance studies or by tissue analysis.

The cause of the episodes of respiratory alkalosis in some cases is difficult to determine but this form of alkalosis may possibly be related to the very high excretion of catecholamines which is found in burns and which may reach levels as high as those found in phaeochromocytoma (Goodall et al., 1957; Birke et al., 1957-8; Harrison, 1967). Whelan and Young (1953) showed that adrenaline and noradrenaline, if given intravenously, produce an increase in respiratory rate and tidal volume. However, Lundholm and Svedmyr (1966) found that intravenous noradrenaline caused a transient respiratory alkalosis, but that adrenaline produced a metabolic acidosis with stimulation of respiration due to an increased production of $\mathrm{CO}_{2}$.

Though it is clear that repeated estimations of the acid-base state and plasma electrolytes are essential for the proper management of patients with severe burns, we have no clinical evidence that a metabolic alkalosis, even of the severity reported here, is harmful. For this reason we made no attempt to correct the alkalosis. Nevertheless we feel that there are many aspects of the metabolic response to severe stress that require further investigation.

Two of us (V.J.C. and E.A.L.) were in receipt of a grant from the Endowment Fund of the United Sheffield Hospitals.

\section{References}

Birke, G., et al. (1957-8). Acta chirurgica Scandinavica, 114, 87.

Goodall, McC., Stone, C., and Haynes, B. W., jun. (1957). Annals of Surgery, 145,479 .

Harrison, J. (1967). Fournal of Trauma, 7, 137.

Hume, D. M., Nelson, D. H., and Miller, D. W. (1956). Annals of Surgery, 143, 316 .

Lundholm, L. and Svedmyr, H. (1966). Acta physiologica Scandinavica, 67, 75. Moore, F. D. (1955). Metabolism, 4, 379.

Muir, I. F. K., and Barclay, T. L. (1963). Burns and their Treatment, p. 28. London, Lloyd Luke.

Siggaard Andersen, O. (1963). Scandinavian fournal of Clinical and Laboratory Investigation, 15, Suppl. No. 70.

Siggaard Andersen, O., and Engel, K. (1960). Scandinavian .7ournal of Clinical and Laboratory Investigation, 12, 177.

Siggaard Andersen, O., Engel, K., Jørgensen, K., and Astrup, P. (1960) Scandinavian fournal of Clinical and Laboratory Investigation, 12, 172.

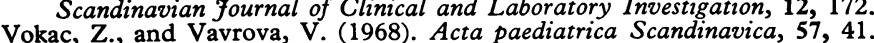
Vokac, Z., and Vavrova, V. (1968). Acta paediatrica Scandinavica, 57, 41. and Chemotherapy, 8, 98. 